\title{
A COMPARATIVE STUDY: IMPACT OF PANDEMIC ON PHARMACEUTICAL SECTORS ACROSS THE GLOBE
}

\author{
Hamza Ebrahim, Naman Jethnani, Sana Shaikh, Tanaz Bilimoria \\ Students, Masters in Finance, NMIMS University, \\ Mumbai, India
}

\begin{abstract}
The following paper analyses the comprehensive impact of COVID-19 as a pandemic on the pharmaceutical sector, by analyzing the effect on indices of 3 countries that were similarly hit. The various indices selected move based on the underlying stocks giving a comprehensive view on the pharma sectors of India, U.S. and U.K. The general assumption would be that the pharmaceutical sector would react to favourable news. However, this is not what we inferred for the countries we researched on for each announcement. The news events taken into consideration include WHO announcing COVID-19 as a pandemic, Oxford University announcing the resuming of trials and the last is the comprehensive effect of the two aforementioned news announcements. The data collected is based on 30 market days before and after the news announcements ranging from 28th January 2020 to 26th October 2020 for the 3 pharma indices respectively. Paired t-test and ANOVA are used to analyze the impact of announcement and degree of variance between the countries for each announcement considered. The various indices of impacted countries showed different reactions to the announcements. None of the countries showed any significant similarity among themselves with respect to the indices.
\end{abstract}

Keywords - Covid-19, Pharmaceutical Index movement, Paired T-Test, ANOVA

\section{INTRODUCTION}

The novel coronavirus disease (COVID-19) was discovered and identified in Wuhan, China in December 2019. On March 11th, the COVID-19 outbreak was characterized as a global pandemic by the World Health Organization (WHO). In the coming months, the pandemic spread rapidly and affected the lives of all living beings across the globe and affected the world economies, including the pharmaceutical sector. While there is no definitive vaccine available to prevent the spread of the disease yet, the healthcare industry has been contributing all the necessary efforts towards treating those infected, spreading awareness, maintaining the supply of medicines and developing treatment tactics in the time of crisis.

The food and drug administrations across the world have seen a significant rise in medical equipment, medication towards COVID-19 symptoms and other related health care products, while there has been a shortage reported among other non
COVID-19 related pharmaceutical products because of the shifted focus on the pandemic.

Furthermore, COVID-19 is seen by some as the century's opportunity for the pharmaceutical sector, due to the increase in demand for prescription medicines, vaccines and medical devices. Identification and analysis of all the above-mentioned effects are essential to provide guidance to the investors and policy makers towards the impact of challenges to be faced by the pharmaceutical sector and draw an outlook over the pharmaceutical sector.

For evaluating the pharmaceutical sector impact at the global level, we analyse the movement in the major pharmaceutical indices caused by the announcements amid the pandemic across various countries.

\section{LITERATURE REVIEW}

Ekta et al. (2020) reported, Investors have chased Indian pharma stocks to their highest levels over the last year. Pharmaceutical sectors have benefited worldwide from the efforts to treat COVID-19 patients. "USFDA approvals of certain drugs for the treatment of the patients and re-rating of the pharmaceutical stocks are the reasons which have caused the upside".

However, according to Surbhi et al. (2020) "The COVID-19 induced lockdown has resulted in a decline in elective surgeries, fall in injectable sales, drop in patients visiting physicians, due to which the pharmaceutical sector is likely to report weakness in earnings in coming quarters of the current fiscal."

Another reason why the pharmaceutical stock upside did not sustain according to M Aravind et al. (2020) in their work discuss that especially in the case of India, "the Indian pharmaceutical companies are dependent to a great extent on Chinese pharmaceutical ingredients. With COVID-19 originating from and having a major impact on China, there has been a break in the supply chain of Indian pharmaceutical companies caused due to scarcity of essential ingredients needed for manufacturing medicines" 3

Dr Thomas et al. (2020) in their work discusses the impact of various sector stocks on the announcement of 21 days lockdown and WHO announcement of declaring COVID 19 epidemic as a pandemic. The effect varied sector to sector, "with financial highest negative followed by the Pharmaceutical sector. All sectors have reported negative performance"4. 


\section{International Journal of Engineering Applied Sciences and Technology, 2020 \\ Vol. 5, Issue 8, ISSN No. 2455-2143, Pages 128-132 \\ Published Online December 2020 in IJEAST (http://www.ijeast.com)}

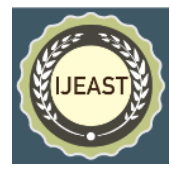

Ayati $\mathrm{N}$ et al. (2020) in their work study the short and long term impacts of the COVID-19 on the pharmaceutical sector on both global and domestic perspectives. According to the research "identifying these impacts is important to guide policymakers in planning and decision making. Proper planning prevents complications and overcomes various challenges towards the optimal utilization of resources"5.

According Baker S et al. (2020) "government restrictions on commercial activity and voluntary social distancing, operating with powerful effects in a service-oriented economy, are the main reasons the U.S. stock market reacted so much more forcefully to COVID-19 than to previous pandemics" ${ }^{6}$ Among other factors, this also needs to be taken into account with respect to change in stock prices.

Another study done on impact of COVID-19 on Indian stock market by Alam M et al. (2020) suggested that "the market reacted positively with significantly positive Average Abnormal Returns during the present lockdown period, and investors anticipated the lockdown and reacted positively, whereas in the pre-lockdown period investors panicked and it was reflected in negative AAR. The study finds evidence of a positive AR around the present lockdown period and confirms that lockdown had a positive impact on the stock market performance of stocks." 7

A study conducted by $\mathrm{Yu} \mathrm{G}$ (2020) indicates the impact of COVID-19 on U.S. stock indices where, "The impact of COVID-19 on the S\&P 500 was dramatic right after the 1st reported case in United States but started to diminish shortly after a one-month quick drop." 8

Chaudhary R et al. (2020) in their discussed the effects of COVID-19 on Indian stock market indices where, "All indices' key findings show lower mean daily return than specific, negative returns in the crisis period compared to the pre-crisis period. The standard deviation of all the indices has gone up, the skewness has become negative, and the kurtosis values are exceptionally large. The relation between indices has increased during the crisis period. The Indian stock market depicts roughly the same standard deviation as the global markets but

has higher negative skewness and higher positive kurtosis of returns, making the market seem more volatile." 9

Another paper by Verma D et al. (2020) investigates if the impact of COVID-19 cases on the market while allowing for the changes in volatility expectation with the effects of the complete lockdown period. "The results suggest that changes in the total number of cases in India do not have a significant impact on mean of Nifty return. However, there is evidence of a positive impact on the conditional variance of the Nifty returns." 10

Alcan G et al. (2020) in their paper recently talk about the interdependency and link between the small scale startups and legacy drug makers with the aim of manufacturing a vaccine for COVID-19. Where, "Financial markets in the time of the coronavirus pandemic hard to predict due to the noise in the markets. Dow Jones Industrial dropped nearly 1,200 points marking the worst intraday point decline in the history of the Dow. The reason for this collapse was a growing consensus that COVID-19 has landed on U.S. shores and will likely have a stronger impact on the economy than the investors initially predicted." $" 11$

\section{RESEARCH PLAN}

\section{Need for the study}

The impact of COVID-19 on the stock markets has been studied by various researchers as discussed above in the literature review. The effects of COVID-19 on the stock markets of countries that have been greatly affected namely; U.S., U.K. \& India has been taken into consideration for this study. The COVID-19 announcements have affected a lot of the sectors listed on the stock market, a few of the sectors have actually gained from this. The Pharmaceutical sector is one of them. The study helps us understand the effects on the sector due to various factors such as panic buying, demand \& stocking for prescribed medications due to which pharma companies will enjoy one-off opportunities arising from COVID-19. Thus the study analyses this impact on pharmaceutical sector stock prices globally.

\section{Objective of the study}

To observe the impact of COVID-19 on pharmaceutical sector prices in India and doing a comparative study with the impact on U.S. \& U.K. pharmaceutical sectors. This has been done by taking into consideration the impact of different events on the pharmaceutical sector by tracking the indices of the respective countries.

\section{Hypothesis \\ Ho(i) (Null Hypothesis): There is no significant change in the indices of each country and between countries based on the announcement of WHO which classified COVID-19 as a pandemic. \\ H1(i) (Alternative hypothesis): There is significant change in the indices of each country and between countries based on the announcement of WHO which classified COVID-19 as a pandemic.}

Ho(ii) (Null Hypothesis): There is no significant change in the indices of each country and between countries based on the announcement of Oxford University resuming trials of the COVID-19 vaccine.

H1(ii) (Alternative hypothesis): There is significant change in the indices of each country and between countries based on the announcement of Oxford University resuming trials of the COVID-19 vaccine.

Ho(iii) (Null Hypothesis): There is no significant change in the indices of each country and between countries before the announcement of WHO which classified COVID-19 as a pandemic \& after the announcement of Oxford University resuming trials of the COVID-19 vaccine. 


\section{International Journal of Engineering Applied Sciences and Technology, 2020 \\ Vol. 5, Issue 8, ISSN No. 2455-2143, Pages 128-132 \\ Published Online December 2020 in IJEAST (http://www.ijeast.com)}

H1(iii) (Alternative hypothesis): There is significant change in the indices of each country and between countries before the announcement of WHO which classified COVID-19 as a pandemic \& after the announcement of Oxford University resuming trials of the COVID-19 vaccine.

(The third hypothesis is done to take an overall impact of COVID-19 up to the writing of the paper in November 2020)

\section{Data collection}

The data that has been collected for the study is subdivided into 3 parts based on the individual countries and their pharmaceutical stock indices. The first country taken is India and the index that has been selected is NIFTY Pharma (CNX Pharma). This index is designed to reflect the behaviour \& performance of the pharmaceutical sector of India, comprising 10 pharma companies listed on NSE. The data for the same has been collected from www.investing.com The next index taken is from the US namely S\&P Pharmaceuticals Select Industry Index (INDEXSP: SPSIPH). The Index comprises stocks in the S\&P Total Market Index that are classified in GICS pharmaceuticals sub-industry comprising of 42 pharmaceutical listed companies. Data for the same has been taken from www.investing.com. The third country taken is the U.K., with the index FTSE 350 Pharmaceuticals \& Biotechnology (FTNMX4570) which tracks 7 U.K. listed pharmaceutical companies that are currently listed on the London Stock Exchange. The data for the same has been collected from www.investing.com.

The study tracks the movement of the indices for a duration of 30 days pre $\&$ post the events taken into consideration. The first being the announcement by WHO which classified COVID-19 as a pandemic (11 ${ }^{\text {th }}$ March 2020). The second event taken into consideration was the day that Oxford University announced the resuming of trials for the COVID19 vaccine that it was developing with pharmaceutical company AstraZeneca (12 $2^{\text {th }}$ September 2020). The third event takes into consideration the total effect of COVID-19 on the indices. This is done by tracking the change in the indices for the 30 days before the announcement by WHO and 30 days post the announcement of the trial being resumed by Oxford University.

\section{Research Methodology}

Research methodology is the technique which one uses to undertake his research with the help of statistical tools in order to attain the desired objective of conducting the research. We have taken the help of inferential statistical techniques to undertake the research. The statistical test we have used in our research for the purpose of testing the hypothesis is Paired ttest and ANOVA.

In a paired t-test, each set of observations or subject is measured twice, thereby giving us a pair of observations. This test compares the impact of a significant event, to analyse the difference between the means of two sets of observations (pre $\&$ post the event).

$$
\mathbf{t}_{\mathrm{cal}}=\frac{\mathbf{d}}{\mathbf{\mathbf { S } _ { \mathbf { d } }} /} \sqrt{\mathbf{n}}
$$

We have conducted the test at a $5 \%$ level of significance. If the calculated value is greater than the tabulated value or if the p-value as tabulated in excel is less than alpha, in that case, we reject the null hypothesis.

On the other hand, if the calculated value so obtained is less than the tabulated value or the p-value is more than alpha, in that case, we accept the null hypothesis.

The aim of our research is to prove the alternate hypothesis. Along with paired t-test, we have used ANOVA to test our research. ANOVA (Analysis of variance) is used for finding out the difference among the population mean by analysing the amount of variation within each sample to the extent of the variation between the samples. By using ANOVA, we assume that each of the samples is drawn from the normal population and each of the population has the same variance. For ANOVA, the two estimates of population variance are compared with F-test.

Here, $\mathrm{F}$ is given as
$\mathrm{F}=\frac{\text { estimate of population variance between the samples }}{\text { an estimate of population variance within the samples }}$

If $F_{\text {cal }}$ is less than $F_{\text {tab }}$ we accept the null hypothesis, else we reject it. We use ANOVA when we have more than 2 samples. ANOVA is used for testing three or more variables. It allows us to make a comparison of more than two groups at the same time and find out if a relationship exists between them.

ANOVA could either be a one-way ANOVA (single factor) or a two-way ANOVA (2 factor). A one-way or two-way factor ANOVA denotes the number of independent variables in the analysis. A one-way ANOVA shows the impact of one factor on one variable. It tells us if there is any significant difference between the means of three or more independent groups. In our research, we have used one-way ANOVA.

\section{ANALYSIS AND FINDINGS}

Below is the results of the analysis.

Table -1 Paired T test for event 1

\begin{tabular}{|c|c|c|c|c|c|c|c|}
\hline \multirow{3}{*}{$\begin{array}{l}\text { Event } 1 \\
\text { Country }\end{array}$} & \multicolumn{7}{|c|}{ WHO declared COVID-19 as a pandemic } \\
\hline & \multicolumn{2}{|c|}{ Mean } & \multicolumn{2}{|c|}{ Variance } & \multirow{2}{*}{ T stat } & \multirow{2}{*}{\begin{tabular}{|l} 
t Critical \\
two-tail
\end{tabular}} & \multirow{2}{*}{ Ho test } \\
\hline & Pre & Post & Pre & Post & & & \\
\hline U.K. & 17120.49 & $\mid 16158.15$ & 360459.74 & 1362111.58 & 7.13 & 2.05 & Reject Ho \\
\hline India & 8116.34 & 7927.7 & 54737.47 & 1381956.36 & 0.95 & 2.05 & Accept Ho \\
\hline U.S. & 8116.34 & $\mid 11757.19$ & 54737.47 & 66308.83 & -63.52 & -2.05 & Reject Ho \\
\hline
\end{tabular}




\section{International Journal of Engineering Applied Sciences and Technology, 2020 \\ Vol. 5, Issue 8, ISSN No. 2455-2143, Pages 128-132 \\ Published Online December 2020 in IJEAST (http://www.ijeast.com)}

Here, as per the results of paired t-test which was applied to find the impact of the announcement of COVID-19 as a pandemic by WHO on the pharma indices of U.K., India \& U.S.

The null hypothesis has been rejected for U.K. (t stat $7.13 \& \mathrm{~T}$ critical 2.05) and U.S. (t stat -63. $52 \&$ T critical- 2.05) at 5\% level of significance. The null hypothesis has been accepted for India (t stat $0.95 \&$ T critical 2.05) at $5 \%$ level of significance.

Thus analysis has shown no significant impact on the pharma index of India, however, it shows a significant impact on U.K. and U.S.

Table -2 Paired T test for event

2

\begin{tabular}{|c|c|c|c|c|c|c|c|}
\hline Event 2 & \multicolumn{7}{|c|}{ Oxford University announces resuming of trial } \\
\hline \multirow{2}{*}{ Country } & \multicolumn{2}{|c|}{ Mean } & \multicolumn{2}{|c|}{ Variance } & \multirow{2}{*}{ T stat } & \multirow{2}{*}{$\begin{array}{l}\text { t Critical } \\
\text { two-tail }\end{array}$} & \multirow{2}{*}{ Ho test } \\
\hline & Pre & Post & Pre & Post & & & \\
\hline U.K. & 17796.66 & \begin{tabular}{|l|}
17431.54 \\
\end{tabular} & \begin{tabular}{|l|}
124533.14 \\
\end{tabular} & 242479.69 & 2.68 & 2.05 & Reject Ho \\
\hline India & 11446.91 & \begin{tabular}{|l|}
11757.19 \\
\end{tabular} & 38877.44 & 66308.83 & -6.61 & -2.05 & Reject Ho \\
\hline U.S. & 5043.39 & 5199.07 & 4039.27 & 30070.39 & -5.03 & -2.05 & Reject Ho \\
\hline
\end{tabular}

Here, as per the results of paired t-test, which was applied to find the impact of the announcement of resuming trials by Oxford University on the pharma indices of U.K., India \& U.S.

The null hypothesis has been rejected for India ( $\mathrm{t}$ stat 2.85 \& $\mathrm{T}$ critical 2.05). UK (t stat $-6.61 \& \mathrm{~T}$ critical- 2.05) and US (t stat - $5.03 \&$ T critical- 2.05) at 5\% level of significance.

Thus analysis has shown no significant impact on the pharma index of India, U.K. and U.S.

Table -3 Paired T test for event 3

\begin{tabular}{|l|l|l|l|l|r|l|l|}
\hline \multirow{2}{*}{ Event 3} & \multicolumn{6}{|c|}{ declared COVID-19 as a pandemic \& Oxford University announces resuming } \\
\hline \multirow{2}{*}{ Country } & \multicolumn{2}{|c|}{ Mean } & \multicolumn{2}{c|}{ Variance } & \multirow{2}{*}{ T stat } & $\begin{array}{l}\text { t Critical } \\
\text { two-tail }\end{array}$ & Ho test \\
\cline { 2 - 8 } & Pre & Post & Pre & Post & & -2.05 & Accept Ho \\
\hline U.K. & 17120.49 & 17431.54 & 360459.74 & 242479.7 & -1.67 & -2.05 & Reject Ho \\
\hline India & 8116.345 & 11757.19 & 54737.47 & 66308.83 & -63.52 & -2.05 & Accept Ho \\
\hline U.S. & 5148.729 & 5199.07 & 93191.13 & 30070.39 & -1.06 & -10 & \\
\hline
\end{tabular}

Here, as per the results of paired t-test which was applied to find the general impact of COVID-19 \& capturing the effect till the date of writing of the paper. This has been done by taking into consideration the pharma index values pre WHO announcement \& post trial resuming announcement. The results of paired t-test that the null hypothesis has been rejected $(\mathrm{T}$ stat $=-63.52, \mathrm{~T}$ crit $=-2.05)$ at $5 \%$ level of significance for India and null hypothesis has been accepted $(\mathrm{T}$ stat $=-1.67, \mathrm{~T}$ crit $=-2.05)$ and $(\mathrm{T}$ stat $=-1.06, \mathrm{~T}$ crit $=-$ 2.05) for UK and US respectively. Thus analysis has shown a significant impact on the pharma index of India. U.K. \& U.S however did not show any significant impact due to these announcements.

\section{Table -4 ANOVA}

\begin{tabular}{|l|l|r|r|r|r|r|}
\hline \multicolumn{5}{|c|}{ Analysis of variance of the index value of various countries during } \\
announcements
\end{tabular}

It could be obtained from the results of one-way analysis of variance that the null hypothesis has been rejected $(\mathrm{F}$ cal $=$ $10.63, \mathrm{~F}$ crit $=3.10$ ) at $5 \%$ level of significance.

Hence, it is inferred that there has been a significant difference among the countries in terms of pharma index value change during the announcement of COVID-19 as a global pandemic by WHO.

It could be obtained from the results of one-way analysis of variance that the null hypothesis has been rejected $(\mathrm{F}$ cal $=$ $17.27, \mathrm{~F}$ crit $=3.10$ ) at $5 \%$ level of significance. Hence, it is inferred that there has been a significant difference among the countries in terms of pharma index value change during the announcement of the trial being resumed by Oxford University.

It could be obtained from the results of one-way analysis of variance that the null hypothesis has been rejected $(\mathrm{F}$ cal $=$ 298.39 , F crit $=3.10$ ) at $5 \%$ level of significance. Hence, it is inferred that there has been significant difference among the countries in terms of pharma index value change with respect to the general impact of COVID-19 \& capturing the effect till the writing of this paper.

\section{CONCLUSION}

The COVID-19 pandemic has had a noteworthy impact on all sectors globally. Having said that, the pandemic cannot simply explain this volatility. Since there is no standard treatment plan for COVID-19 nor has there been any development in terms of the vaccine, yet the pharma sector has seen significant volatility in terms of its price movement across the globe.

The general outlook for pharma sectors across the world would be that this pandemic would bring a once in a lifetime 
opportunity for these companies. The general assumption would be that the pharma sector would react to favourable news.

However, this is not what we inferred was the case for the countries we researched on for each announcement.

The announcement by WHO, classifying COVID-19 as a pandemic has shown a significant impact on the U.S. \& U.K. pharma sectors. India, however, has little to no movement in the pharma sector that can be explained by this announcement. On the other hand, all the countries showed a significant impact due to the announcement by oxford resuming trial of COVID vaccine. The trials had halted due to a participant having a suspected adverse reaction in the U.K. to the vaccine. The news of resuming trials acted as a glimmer of hope to the homebound population.

On doing a study for the pharmaceutical sector impact for over a tenure of pandemic (up to writing of this paper). Only the Indian pharmaceutical index showed a significant impact whereas U.K. \& U.S. showed no significant impact.

On doing a comparative study of variation in the pharmaceutical sector across the countries, the news announcements showed significant variance between the countries examined, to the point where the reactions were not similar to each other.

This study is based on impactful events till the month of November 2020. A comprehensive study of the effects of COVID-19 as a global pandemic on the pharma sector can only be done once the situation becomes more viable.

\section{REFERENCE}

[1] Batra Ekta (2020). COVID-19 side effect: Key Indian pharma shares hit 52-week highs, www.cnbctv18.com.

[2] Jain Surbhi (2020). Pharma earnings to reflect full COVID-19 impact in Apr-Jun quarter; 4 pharma stocks to gain up to $16 \%$, www.financialexpress.com

[3] M Aravind and C G Manojkrishnan (2020). COVID 19: Effect on leading pharmaceutical stocks listed with NSE, DOI: 10.26452/ijrps.v11iSPL1.2014

[4] Dr Thomas T.C., Dr Sankararaman G. and Dr Suresh S. (2020). Impact of COVID-19 announcement on nifty stocks, DOI: 10.31838/jcr.07.13.83

[5] Ayati N, Saiyarsarai P and Nikfar S. (2020). Short and long term impacts of COVID-19 on the pharmaceutical sector. DOI: 10.1007/s40199-020-00358-5

[6] Baker S, Bloom N, Davis S, Kost K, Sammon M, and Viratyosin T. (2020). The Unprecedented Stock Market Reaction to COVID-19. DOI:10.1093/rapstu/raaa008.

[7] Alam M, Alam S and Chavali K. (2020). Stock Market Response during COVID-19 Lockdown Period in India: An Event Study. DOI: 10.13106/jafeb.2020.vol7.no7.131
[8] Yu G. (2020). Comparative Analysis of COVID-19 Trend, Impact on S\&P 500, and S\&P 500 Forecasting. ISSN 0976-5891 Volume 12, Number 1 (2020), (Pg 1-7).

[9] Chaudhary R, Bakhshi P and Gupta H. (2020). The performance of the Indian stock market during COVID19. DOI: 10.21511/imfi.17(3).2020.11

[10] Verma D and Sinha P. (2020). Has COVID 19 Infected Indian Stock Market Volatility? Evidence from NSE. (Pg 1-21)

[11] Alcan G, Ozdurak C and Guvenbas S. (2020). The Impact of Covid-19 to Global Pharmaceuticals and Biotechnology Company Stocks Returns. DOI:10.17261/Pressacademia.2020.1215

[12] Investing.com for data, www.investing.com 